\title{
Triblock copolyesters derived from lactic acid and glucose: Synthesis, nanoparticle formation and simulation
}

\author{
Elena Zakharova, ${ }^{1}$ Salvador León, ${ }^{2}$ \\ Antxon Martínez de Ilarduya, ${ }^{1}$ and Sebastián Muñoz-Guerra ${ }^{1}$ \\ ${ }^{1}$ Departament d'Enginyeria Química, Universitat Politècnica de Catalunya, \\ ETSEIB, Diagonal 647, 08028 Barcelona, Spain \\ ${ }^{2}$ Departamento de Ingeniería Química, Universidad Politécnica de Madrid, \\ ETSIIM, Gutiérrez Abascal 2, 28006 Madrid, Spain \\ Corresponding author: sebastian.munoz@upc.edu
}

\begin{abstract}
ABA triblock copolyesters were synthesized by ring-opening polymerization (ROP) of L-lactide in solution initiated by a telechelic D-glucose-based polyester macroinitiator. The macroinitiator with a number-average molecular weight about $2,500 \mathrm{~g} \cdot \mathrm{mol}^{-1}$ was synthesized by nonstoichiometric polycondensation in the melt of 2,4:3,5-di-O-methylene-D-glucitol and dimethyl succinate. Two triblock copolyesters of $M_{\mathrm{n}}$ ranging between $\sim 6,000$ and $\sim 9,000 \mathrm{~g} \cdot \mathrm{mol}^{-1}$, and differing in the length of the polylactide blocks were prepared. These copolyesters started to decompose when heated at $\sim 220^{\circ} \mathrm{C}$ and degraded slowly upon aqueous incubation under physiological conditions. They did not display any perceivable crystallinity and showed a single glass transition temperature $\left(T_{\mathrm{g}}\right)$ around $60{ }^{\circ} \mathrm{C}$ with the higher value corresponding to the larger content in glucitol units. The copolyesters were able to form nanoparticles with average diameters of $\sim 100-130 \mathrm{~nm}$ and satisfactory dispersity. The effect of the block lengths on size, $\zeta$-potential values and physical stability of the nanoparticles was evaluated. A molecular dynamics simulation study allowed modeling the two-phase structure of the nanoparticles and evidenced the preference of the glucose-based block to be peripherally located.
\end{abstract}

Key words: lactic block copolyester; gludioxol block copolyester; glucose derived copolyester; amphiphilic triblock copolyester; bio-based triblock copolyester, block copolyester nanoparticles 


\section{Introduction}

Biodegradable and biocompatible polymers are today the products of choice to build biomaterials that are intended to be used for temporal applications [1-3]. Aliphatic polyesters are doubtlessly the polymer family mostly used for such purposes [4-6]. These polymers may be prepared in many cases from renewable feedstock by relatively simple procedures, and their thermal and mechanical properties may be tuned in a great extent by either proper selection of the monomers, or by copolymerization adjusting the copolymer composition. Among aliphatic polyesters, those derived from lactic acid, which are commonly known as polylactides (PLA), are outstanding due to their bio-based origin and exceptionally low immunogenicity $[7,8]$. In fact, the literature is plenty of reports dealing with the potential application of PLA and its copolymers in the biomedical field as a variety of prostheses and scaffolds, and as drug delivery systems [9-11].

The present paper is concerned with triblock copolyesters of PLA and their potential application in the preparation of particles, more specifically structured nanoparticles with interest as drug carriers. It is well known that the precise synthesis of self-assembling polymeric systems is able to provide a good control over the resulting nanostructure. In this regard, amphiphilic block or graft copolymers are particularly suitable because they may be arranged in nanostructures with separated phases capable to embed specifically either hydrophobic or hydrophilic compounds. Block copolyesters based on polylactides stand out in this field due to their favorable physicochemical characteristics in terms of safety, stability, large-scale production, and lack of intrinsic immunogenicity $[12,13]$. Nanostructurated PLAbased particles are usually achieved when the lactide is copolymerized with a comonomer able to generate a highly hydrophilic polymer block [14], such as polyether [15] or polypeptide [16]. Incompatibility of this block with the relatively hydrophobic polylactide block promotes phase segregation and concomitant generation of shell-core particles.

In this paper we want to report on triblock copolyesters made of a hydrophilic block of poly(glucitylene succinate) (PGluxSucc) attached to two dangling hydrophobic PLA blocks. $\mathrm{P}$ (GluxSucc) is synthesized by melt polycondensation of 2,4;3,5-di-O-methylene-D-glucitol 
(Glux-diol) and dimethyl succinate. Glux-diol is a bicyclic diacetal derived from D-glucose that has been extensively explored by us as a bio-based comonomer appropriate for the synthesis of aromatic and aliphatic copolyesters $[17,18]$. The homopolyester $\mathrm{P}($ GluxSucc) is reported to be a hydrophilic biodegradable polymer that is unable to crystallize and that has a $T_{\mathrm{g}}$ about $100{ }^{\circ} \mathrm{C}$ [18]. The novelty of the approach followed in this work relies on the fact that whereas racemic PLA and $\mathrm{P}$ (GluxSucc) are compatible in the bulk or in films prepared by casting, the two blocks become segregated when they are confined in particles that are generated by emulsion in an aqueous environment. This paper describes the synthesis and characterization of the triblock PLA-P(GluxSucc)-PLA copolyesters and explores the formation of nanospheres paying particular attention to the effect of the length of the blocks on their thermal properties, particle size, $\zeta$-potential and physical stability. The experimental work is supported by a modelling study carried out by molecular dynamics that is addressed to substantiate the existence of differentiated phase domains in the copolyester nanoparticles.

\section{Experimental part}

\subsection{Materials}

The reagents dimethyl succinate (DMS, > 99\%), (3S,6S)-3,6-dimethyl-1,4-dioxane-2,5dione (L-lactide, 98\%), dibutyl tin oxide (DBTO, 98\%) and 1,5,7-triazabicyclo[4.4.0]dec-5-ene (TBD, 98\%) were purchased from Sigma-Aldrich. Solvents used for purification, synthesis and characterization were all of either technical or high-purity grade, and they were purchased from Panreac and used as received without further purification. The bicyclic diol 2,4:3,5-di-Omethylene-D-glucitol (Glux-diol) was prepared by a procedure described recently by us [19].

\subsection{General methods}

${ }^{1} \mathrm{H}$ and ${ }^{13} \mathrm{C}$ NMR spectra were recorded on a Bruker AMX-300 spectrometer at $25.0{ }^{\circ} \mathrm{C}$ operating at 300.1 and $75.5 \mathrm{MHz}$, respectively. Samples of about 10 or $50 \mathrm{mg}$ of polyester dissolved in $1 \mathrm{~mL}$ of deuterated chloroform were used for ${ }^{1} \mathrm{H}$ and ${ }^{13} \mathrm{C}$ NMR, respectively, and they were internally referenced to tetramethylsilane (TMS). Sixty-four scans for ${ }^{1} \mathrm{H}$ and $1,000-$ 10,000 scans for ${ }^{13} \mathrm{C}$ with 32 and $64-\mathrm{K}$ data points with relaxation delays of 1 and $2 \mathrm{~s}$, 
respectively, were registered. Gel permeation chromatograms were acquired at $35.0^{\circ} \mathrm{C}$ using a Waters equipment provided with a refraction-index detector. The samples were chromatographed using $0.05 \mathrm{M}$ sodium trifluoroacetate-hexafluoroisopropanol mixture (NaTFA-HFIP) as mobile phase trough a gel column $(300 \times 7.5 \mathrm{~mm})$ with a flow rate of 0.5 $\mathrm{mL} \cdot \mathrm{min}^{-1}$. Chromatograms were calibrated against poly(methyl methacrylate) monodisperse standards. The thermal behavior of polyesters was examined by DSC from 3 to $5 \mathrm{mg}$ samples using a Perkin Elmer DSC8000 apparatus at heating/cooling rates of $10^{\circ} \mathrm{C} \cdot \mathrm{min}^{-1}$, and under a nitrogen flow of $20 \mathrm{~mL} \cdot \mathrm{min}^{-1}$. Indium and zinc were used as standards for temperature and enthalpy calibrations. Glass-transition temperatures were determined by the tangent method from melt-quenched polymer samples at a heating rate of $20^{\circ} \mathrm{C} \cdot \mathrm{min}^{-1}$. Matrix-assisted laser desorption ionization time-of-flight mass spectrometry (MALDI-TOF MS) was performed using a ABSciex 4800 plus MALDI TOF/TOF mass spectrometer. The spectrometer was equipped with a Nd:YAG laser. The detection was in the reflection mode and positive ionization was used. Thermogravimetric analyses were performed on a Mettler Toledo TGA/DSC 1 thermobalance under a nitrogen flow of $20 \mathrm{~mL} \cdot \mathrm{min}^{-1}$ at a heating rate of $10^{\circ} \mathrm{C} \cdot \mathrm{min}^{-1}$ within a temperature range of 30 to $600{ }^{\circ} \mathrm{C}$. Sample weights of about $10-15 \mathrm{mg}$ were used in these experiments. Scanning electron microscopy images were taken with a field-emission JEOL JSM-7001F instrument (JEOL, Japan) from platinum/palladium coated (PMLA/DOX conjugates) and uncoated samples. Dynamic light scattering for particle hydrodynamical size and $\zeta$-potential measurements were performed with the Brookhaven NanoBrook, particle/protein size and zeta potential analyzer (Brookhaven Instruments Corporation, USA) with particles suspended in deionized water.

\subsection{Synthesis of telechelic $\mathrm{OH}-\mathrm{P}(\mathrm{GluxSucc})_{\mathrm{x}}-\mathrm{OH}$ homopolyester}

The hydroxyl capped telechelic homopolyester was synthesized by melt polycondensation of dimethyl succinate with Glux-diol using a $10 \%$-mole excess of diol respect to the diester. The reaction was carried out in a three-necked, cylindrical bottom flask equipped with a mechanical stirrer, a nitrogen inlet and a vacuum distillation outlet. The 
reactants were stirred to get a homogeneous mixture of the two reagents and then DBTO (0.4$0.6 \%$-mole respect to the total of monomers) was added as catalyst. The two-steps reaction proceeded through transesterification at $175^{\circ} \mathrm{C}$ for $4 \mathrm{~h}$ under a nitrogen flow followed by polycondensation at the same temperature for $2 \mathrm{~h}$ under vacuum (0.03-0.06 mbar). Finally the reaction mixture was cooled to room temperature under a nitrogen flow to prevent degradation and the resulting solid mass was dissolved in chloroform. The polymer was precipitated with methanol, collected by filtration and dried under vacuum. The NMR data ascertaining their constitution and purity are described below.

$\mathrm{OH}-\mathrm{P}(\mathrm{GluxSucc})_{x} \mathrm{OH}$ homopolyester: ${ }^{1} \mathrm{H}$ NMR (300.1 MHz, $\left.\mathrm{CDCl}_{3}\right), \delta(\mathrm{ppm}): 5.2-4.8(\mathrm{~m}, 4 \mathrm{H}$, $\left.\mathrm{OCH}_{2} \mathrm{O}\right), 4.6-4.2\left(\mathrm{~m}, 2 \mathrm{H}, \mathrm{OCH}_{2} \mathrm{CH}\right), 4.4-4.2\left(\mathrm{~m}, 4 \mathrm{H}, \mathrm{OCH}_{2} \mathrm{CH}\right), 4.2\left(\mathrm{~m}, 1 \mathrm{H}, \mathrm{OCH}_{2} \mathrm{CHCH}\right), 3.9$ (m, $\left.1 \mathrm{H}, \mathrm{OCH}_{2} \mathrm{CHCH}\right), 3.8\left(\mathrm{~m}, 1 \mathrm{H}, \mathrm{OCH}_{2} \mathrm{CHCH}\right), 3.6\left(\mathrm{~m}, 1 \mathrm{H}, \mathrm{OCH}_{2} \mathrm{CHCHCHCH}\right), 2.7(\mathrm{~m}, 4 \mathrm{H}$, $\left.\mathrm{COCH}_{2} \mathrm{CH}_{2} \mathrm{CO}\right) .{ }^{13} \mathrm{C}$ NMR (75.5 MHz, $\mathrm{CDCl}_{3}$ ), $\delta$ (ppm): 176.7 (CO), 93.2, 88.3, 76.2, 74.5, $71.5,68.4,67.0,61.8,20.9$.

\subsection{Synthesis of $P L A_{y}-P(\text { GluxSucc })_{x}-P L A_{y}$ triblock copolyesters}

Briefly, the calculated amount of $\mathrm{OH}-\mathrm{P}(\mathrm{GluxSucc})_{\mathrm{x}}-\mathrm{OH}$ was added to a $1 \mathrm{M}$ solution of Llactide in dichloromethane at $25^{\circ} \mathrm{C}$ in a round bottom three-necked flask and the mixture stirred until complete solution. Then TBD (5\%-mole relative to the lactide) was added and the solution was further stirred for 5 min under a nitrogen atmosphere at the same temperature. The triblock copolyester was precipitated with methanol, collected by filtration and dried under vacuum. Two copolyesters $P L A_{y}-P(G l u x S u c c) x-P L A_{y}$ with $y / x$ ratios of approximately 2 and 3.5 were obtained by this procedure.

$P L A_{y}-P(\text { GluxSucc) })_{x}-P L A_{y}$ block copolyesters: ${ }^{1} \mathrm{H}$ NMR (300.1 MHz, $\left.\mathrm{CDCl}_{3}\right), \delta(\mathrm{ppm}): 5.2-4.8$ $\left(\mathrm{m}, 4 \mathrm{H}, \mathrm{x} \cdot \mathrm{OCH}_{2} \mathrm{O}\right), 5.2\left(\mathrm{~m}, \mathrm{y} \cdot 1 \mathrm{H}, \mathrm{OCHCH}_{3}\right), 4.6-4.2\left(\mathrm{~m}, \mathrm{x} \cdot 2 \mathrm{H}, \mathrm{OCH}_{2} \mathrm{CH}\right), 4.4-4.2(\mathrm{~m}, \mathrm{x} \cdot 4 \mathrm{H}$, $\left.\mathrm{OCH}_{2} \mathrm{CH}\right), 4.2\left(\mathrm{~m}, \mathrm{x} \cdot 1 \mathrm{H}, \mathrm{OCH}_{2} \mathrm{CHCH}\right), 3.9\left(\mathrm{~m}, \mathrm{x} \cdot 1 \mathrm{H}, \mathrm{OCH}_{2} \mathrm{CHCH}\right), 3.8\left(\mathrm{~m}, \mathrm{x} \cdot 1 \mathrm{H}, \mathrm{OCH}_{2} \mathrm{CHCH}\right)$, $3.7\left(\mathrm{~m}, \mathrm{x} \cdot 1 \mathrm{H}, \mathrm{OCH}_{2} \mathrm{CHCHCHCH}\right), 2.7\left(\mathrm{t}, \mathrm{x} \cdot 4 \mathrm{H}, \mathrm{COCH}_{2} \mathrm{CH}_{2} \mathrm{CO}\right), 1.5\left(\mathrm{~d}, \mathrm{y} \cdot 3 \mathrm{H}, \mathrm{OCHCH}_{3}\right) \cdot{ }^{13} \mathrm{C}$ NMR (75.5 MHz, $\mathrm{CDCl}_{3}$ ), $\delta$ (ppm): 172.0 (CO), 169.6 (CO), 92.9, 88.4, 75.3, 73.7, 70.8, 69.0, $67.2,63.4,61.0,29.0,16.66$. 


\subsection{Synthesis of PLA homopolyester}

Benzyl alcohol (1.6 \%-mole relative to the lactide) was added to a $1 \mathrm{M}$ solution of Llactide in dichloromethane at $25^{\circ} \mathrm{C}$ in a round bottom three-necked flask and the mixture stirred until complete solution. Then TBD ( $5 \%$-mole relative to the lactide) was added and the solution was further stirred for 5 min under a nitrogen atmosphere at the same temperature. The homopolyester was precipitated with hexane, collected by filtration and dried under vacuum.

PLA homopolyester: ${ }^{1} \mathrm{H}$ NMR (300.1 MHz, $\left.\mathrm{CDCl}_{3}\right), \delta(\mathrm{ppm}): 5.2\left(\mathrm{~m}, 1 \mathrm{H}, \mathrm{OCHCH}_{3}\right), 1.5(\mathrm{~m}, 3 \mathrm{H}$, $\left.\mathrm{OCHCH}_{3}\right) .{ }^{13} \mathrm{C}$ NMR $\left(75.5 \mathrm{MHz}, \mathrm{CDCl}_{3}\right), \delta(\mathrm{ppm}): 172.0$ (CO), 69.0, 16.7.

\subsection{Hydrolytic degradation and biodegradation}

Films for hydrolytic degradation and biodegradation studies were prepared with a thickness of $\sim 200 \mu \mathrm{m}$ by casting from a chloroform solution with a polymer concentration of $100 \mathrm{~g} \cdot \mathrm{L}^{-1}$. The films were cut into $10 \mathrm{~mm}$-diameter and $20 \mathrm{mg}$-weight disks which were then dried under vacuum to constant weight. For hydrolytic degradation, the disks were incubated in vials containing $10 \mathrm{~mL}$ of sodium phosphate buffer $\mathrm{pH} 7.4$ at $37{ }^{\circ} \mathrm{C}$. The enzymatic degradation was carried out under the same conditions but in the presence of $10 \mathrm{mg}$ of lipase from porcine pancreas and replacing the supernatant every $72 \mathrm{~h}$ in order to maintain the enzyme activity. In both cases, disks were withdrawn from the incubation medium at scheduled periods of time, washed carefully with distilled water, dried to constant weight, and analyzed by GPC chromatography and NMR spectroscopy.

\subsection{Preparation of nanoparticles}

Nanoparticles of $\mathrm{PLA}_{y}-\mathrm{P}(\text { GluxSucc })_{x}-\mathrm{PLA}$ were prepared by the precipitation-dialysis method. $5 \mathrm{mg}$ of the block copolymer were dissolved in $1 \mathrm{~mL}$ of DMSO and the same volume of water added to yield a translucent solution. This solution was dialyzed against distilled water for $72 \mathrm{~h}$ at room temperature using cellulose membrane tubes (2000 molecular weight cut-off) with frequent replacement of the external medium. The particles generated upon dialysis were subjected to SEM examination and light-scattering measurements. 


\subsection{Simulation studies}

Molecular dynamics simulations in water solution have been carried out for model nanoparticles made up of copolymer chains with different sequences. Due to the large size of the systems under consideration, as well as the large time scales involved, the MARTINI [20] coarse-grained force-field with explicit polarizable water solvent [21] has been used in the simulations. Each mesoscopic simulation consisted on 15 ns of equilibration, and 15 ns of production run, with a time step of $0.03 \mathrm{ps}$, in the NVT ensemble at $300 \mathrm{~K}$.

Energy parameters within the MARTINI CG model for the copolymers under study have been taken by fitting the results to short atomistic molecular dynamics simulations performed on model systems of limited size, i.e. PLA 6 - $(\text { GluxSucc })_{12}-P L A_{6}$ chains, in a box of solvent. The GROMOS [22] force-field has been used in the atomistic simulation, where the energy parameters for the three types of residue have been obtained through the ATB [23-25] online tool. All the atomistic and mesoscopic simulations have been carried out with the GROMACS [26] package.

\section{Results and discussion}

\subsection{Synthesis and chemical structure}

The synthetic route followed in this work to obtain the triblock copolyesters is depicted in Scheme 1. 2,4:3,5-di-O-methylene-D-glucitol (Glux-diol) was prepared from commercially available 1,5-D-gluconolactone with satisfactory yield and high purity by a synthesis procedure previously reported by us [19]. The $\mathrm{OH}-\mathrm{P}(\mathrm{GluxSucc})_{\mathrm{x}}-\mathrm{OH}$ telechelic homopolyester was synthesized by a two-steps polymerization reaction in the melt from Glux-diol and dimethyl succinate assisted by DBTO catalyst. An excess of $10 \%$-mole of Glux-diol was used in order to generate hydroxyl capped oligoesters containing around ten repeating units. The first step was carried out under a nitrogen flow to sweep off the methanol generated by transesterification. The second step was carried out under vacuum to remove the remaining methanol. ${ }^{1} \mathrm{H}$ and ${ }^{13} \mathrm{C}$ spectra of $\mathrm{OH}-\mathrm{P}(\text { GluxSucc })_{\mathrm{x}}-\mathrm{OH}$ homopolyester with indication of all signals assignments are provided in the ESI file. These spectra ascertained the chemical 
constitution expected for this telechelic homopolyester and a comparative quantification of the proton resonance signals arising from inner and end glucitylene units was used to estimate its number average polymerization degree which resulted to be about 12 . These data were well supported by MALDI-TOF spectra which showed peaks regularly separated by $288 \mathrm{~m} / \mathrm{z}$ corresponding to the GluxSucc repeating unit and at values that included the additional ending Glux-OH (see ESI file).

Triblock copolyesters $\mathrm{PLA}_{y}-\mathrm{P}(\mathrm{GluxSucc})_{x}-\mathrm{PLA}_{y}$ were synthesized by ring-opening polymerization of L-lactide in the presence of $\mathrm{OH}-\mathrm{P}(\text { GluxSucc })_{x}-\mathrm{OH}$ which operated as a double macroinitiator. In order to prevent undesirable transesterifications leading to randomization, the reaction was carried out at $25^{\circ} \mathrm{C}$ in solution. The amounts of lactide and $\mathrm{OH}-\mathrm{P}(\mathrm{GluxSucc})_{12}-\mathrm{OH}$ made to react were accurately adjusted to target copolyesters with two selected $\mathrm{y} / \mathrm{x}$ ratios, i.e. 2 and 3.5 .



Scheme 1. Synthetic route leading to PLA $-\mathrm{P}(\text { GluxSucc })_{x}-\mathrm{PLA}_{y}$ triblock copolyesters.

The strategy followed in this work to synthesize the block structure was especially suitable for a triblock design since the poly(glucitylene succinate) telechelic with two ending hydroxyl groups could be readily prepared. In the triblock structure, the mobility of the glucitylene succinate segment is more restricted than it would be in a diblock structure and therefore a higher particle stability can be expected. Additionally, the occurrence of hydrophilic segments dangling from the particle surface is minimized. 
The chemical constitution and composition of the triblock copolyesters synthesized in this work were definitely ascertained by NMR. The ${ }^{1} \mathrm{H}$ and ${ }^{13} \mathrm{C}$ NMR spectra of PLA $24^{-}$ $\mathrm{P}$ (GluxSucc) $)_{12}-\mathrm{PLA}{ }_{24}$ copolyester are depicted in Fig.1 for illustrating purposes, and those recorded for its $\mathrm{PLA}_{40}-\mathrm{P}(\text { GluxSucc })_{12}-\mathrm{PLA}_{40}$ homologue are included in the ESI file. All signals could be straightforwardly assigned and no significant peaks revealing the presence of impurities were present in these spectra. Particular attention is deserved by the resonance arising from the methylene protons in the two dioxolane rings because their different magnetic environment. The assignment of signals corresponding to these two methylene hydrogen pairs was supported by 2D NMR analysis and cosy and noesy spectra are included in the ESI file. It is well-known that NMR spectra of polymers are sensitive to neighboring and configurational effects. Stereoregular poly(L-lactic acid) is characterized by a quadruplet corresponding to methine group at $5.2 \mathrm{ppm}$ and a doublet arising from the methyl group at $1.5 \mathrm{ppm}$. The simultaneous presence of $D$ and L-lactate units will give rise to complex NMR spectra with lactate signals more or less split according to the different types of stereosequence present in the blocks. In fact, it could be observed that the ${ }^{1} \mathrm{H}$ spectra of $P L A_{y}-P(G l u x S u c c){ }_{12}-P L A_{y}$ copolyesters as well as those of the PLA homopolyester contain multiplet peaks in the regions assigned to PLA blocks, proving the occurrence of a certain racemization of the L-lactide during polymerization. Conversely no additional succinate signals revealing the occurrence of transesterification reaction were detected in the copolyesters spectra.

Copolyester compositions were determined by integration of the proton signals arising from the respective block units. The obtained values were fairly close to those used in the respective feeds, which leads to conclude that L-lactide must have reacted almost completely by ROP. The characteristic peaks at 4.0 and $3.7 \mathrm{ppm}$ corresponding to $-\mathrm{CH}_{2} \mathrm{OH}$ terminal groups disappeared as the conversion of $\mathrm{OH}-\mathrm{P}(\mathrm{GluxSucc})_{12}-\mathrm{OH}$ increased confirming the formation of ester functions (see details in the ESI file). GPC measurements showed that polyesters were obtained with weight average molecular weights in the 4,000-10,000 $\mathrm{g} \mathrm{mol}^{-1}$ range with dispersity indexes oscillating between 1.4 and 1.7. Average number molecular weights of copolyesters measured by GPC resulted to be slightly lower than those determined 
by ${ }^{1} \mathrm{H}$ NMR end group analysis; an inconsistency that can be accounted by the inaccuracy inherent to the chromatographic method when standards are used for calibration. Composition and molecular weight data obtained for the telechelic homopolyester and the triblock copolyesters are collected in Table 1.

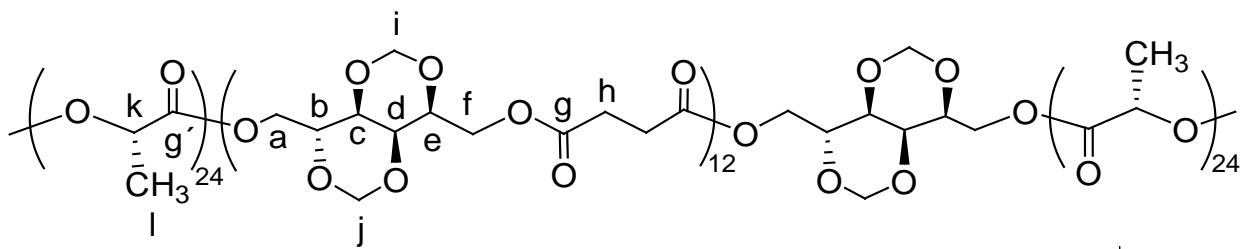

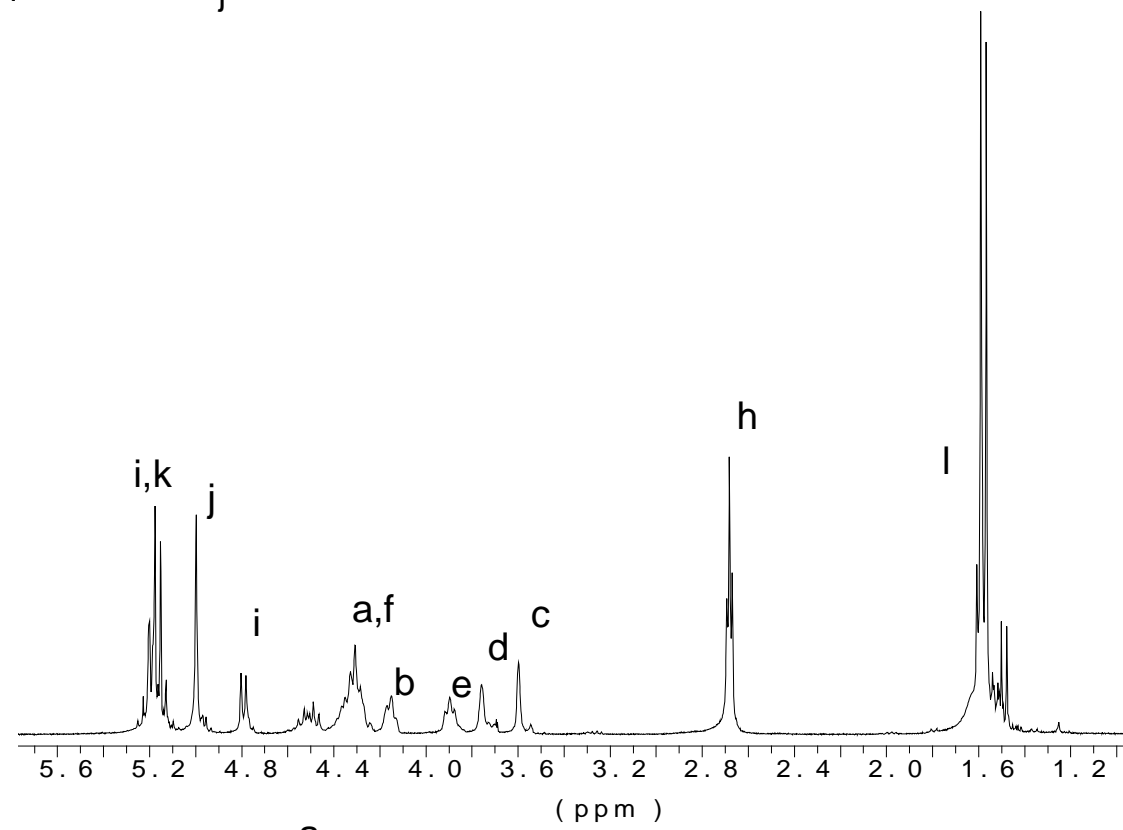

a

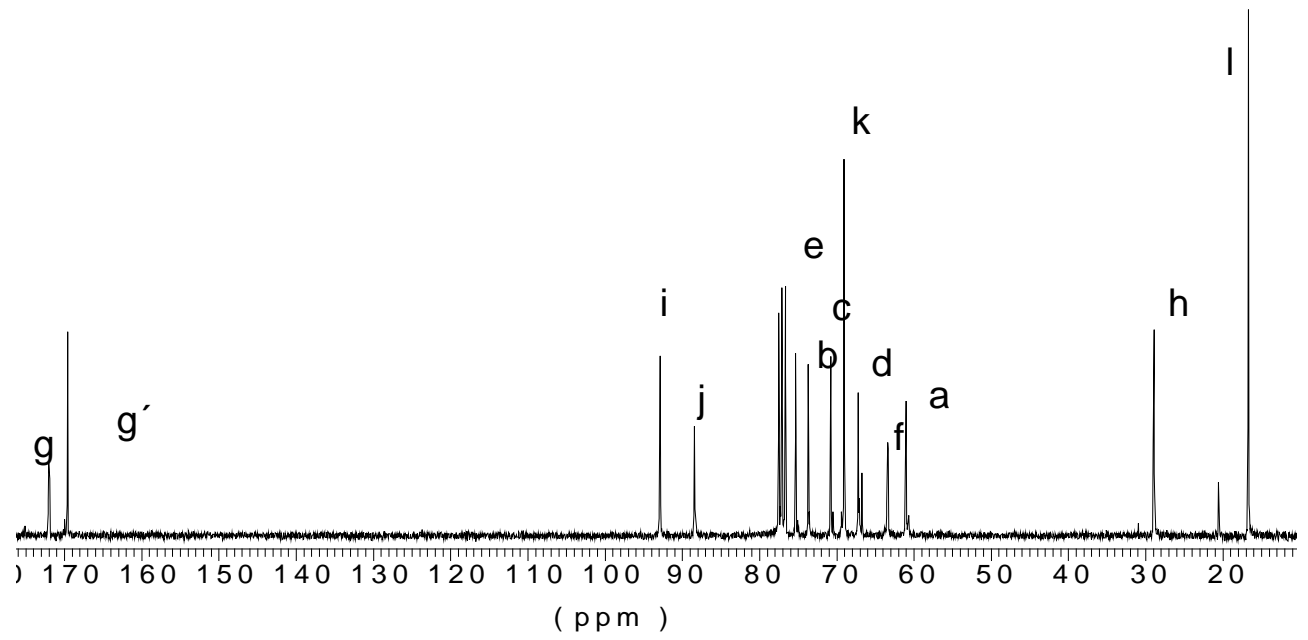

Fig. 1. ${ }^{1} \mathrm{H}$ (top) and ${ }^{13} \mathrm{C}$ (bottom) spectra of $\mathrm{PLA}_{24}-\mathrm{P}(\mathrm{GluxSucc}){ }_{12}-\mathrm{PLA}_{24}$ triblock copolyester. 
Table 1. Composition and molecular weights of homopolyesters and triblock copolyesters.

\begin{tabular}{|c|c|c|c|c|c|c|}
\hline \multirow[t]{2}{*}{ Polyester } & \multicolumn{2}{|c|}{$\begin{array}{c}\text { Composition }^{\mathrm{a}} \\
\text { ([LA] / [GluxSucc] }^{2}\end{array}$} & \multicolumn{4}{|c|}{$\begin{array}{l}\text { Molecular weight } \\
\left(\mathrm{g} \cdot \mathrm{mol}^{-1}\right)\end{array}$} \\
\hline & Feed & Copolyester ${ }^{a}$ & $M_{\mathrm{n}}^{b}$ & $M_{\mathrm{n}}{ }^{c}$ & $M_{\mathrm{w}}{ }^{c}$ & $\Theta^{c}$ \\
\hline$\overline{\mathrm{OH}-\mathrm{P}(\mathrm{GluxSucc})_{12}-\mathrm{OH}}$ & $0 / 100$ & $0 / 100$ & 3500 & 2600 & 4500 & 1.7 \\
\hline $\mathrm{PLA}_{24}-\mathrm{P}(\text { GluxSucc })_{12}-\mathrm{PLA}_{24}$ & $80.0 / 20.0$ & $81.0 / 19.0$ & 6900 & 5500 & 7700 & 1.4 \\
\hline $\mathrm{PLA}_{40}-\mathrm{P}(\text { GluxSucc })_{12}-\mathrm{PLA}_{40}$ & $87.0 / 13.0$ & $88.0 / 12.0$ & 9200 & 6800 & 9400 & 1.4 \\
\hline PLA & $100 / 0$ & $100 / 0$ & 8100 & 4400 & 10900 & 2.5 \\
\hline
\end{tabular}

${ }^{2}$ Molar composition in the feed and in the copolyester determined by integration of ${ }^{1} \mathrm{H}$ NMR spectra.

${ }^{\mathrm{b}}$ Molecular weights calculated by ${ }^{1} \mathrm{H}$ NMR.

${ }^{\mathrm{C}}$ Molecular weights and dispersities determined by GPC against PMMA standards.

\subsection{Thermal properties}

The thermal behaviour of the telechelic homopolyester and the two triblock copolyesters has been comparatively studied by thermal gravimetric analysis (TGA) and differential scanning calorimetry (DSC). The main thermal parameters recorded from these assays are collected in Table 2.

Table 2. Thermal properties of the polyesters.

\begin{tabular}{|c|c|c|c|c|c|c|}
\hline \multirow[t]{2}{*}{ Polyester } & \multicolumn{3}{|c|}{$T_{G A}{ }^{a}$} & \multicolumn{3}{|c|}{$\mathrm{DSC}^{\mathrm{b}}$} \\
\hline & ${ }^{\circ} T_{d}\left({ }^{\circ} \mathrm{C}\right)$ & $\begin{array}{c}{ }^{\max } T_{\mathrm{d}} \\
\left({ }^{\circ} \mathrm{C}\right)\end{array}$ & $\begin{array}{l}R W \\
\text { (\%) }\end{array}$ & $\begin{array}{c}T_{\mathrm{g}} \\
\left({ }^{\circ} \mathrm{C}\right)\end{array}$ & $\begin{array}{c}T_{\mathrm{m}} \\
\left({ }^{\circ} \mathrm{C}\right)\end{array}$ & $\underset{\left(\mathrm{J} \cdot \mathrm{g}^{-1}\right)}{\Delta H}$ \\
\hline $\mathrm{OH}-\mathrm{P}(\mathrm{GluxSucc})_{12}-\mathrm{OH}$ & $316^{*}$ & 398 & 11 & 94 & - & - \\
\hline $\mathrm{PLA}_{24}-\mathrm{P}(\text { GluxSucc })_{12}-\mathrm{PLA}_{24}$ & 223 & $287 / 395$ & 6 & 61 & - & - \\
\hline $\mathrm{PLA}_{40}-\mathrm{P}(\text { GluxSucc })_{12}-\mathrm{PLA} 40$ & 216 & $278 / 347 / 384$ & 8 & 58 & - & - \\
\hline PLA & 218 & 283 & 5 & 40 & - & - \\
\hline
\end{tabular}

${ }^{\mathrm{a}}$ Onset decomposition temperature corresponding to $5 \%$ of weight loss $\left({ }^{\circ} T_{\mathrm{d}}\right)$, temperature of maximum legradation rate $\left({ }^{\max } T_{\mathrm{d}}\right)$ and weight $(\%)$ remaining after heating at $600{ }^{\circ} \mathrm{C}(R W)$. *Before experiment telechelic homopolyester was heated at $130{ }^{\circ} \mathrm{C}$ during $5 \mathrm{~min}$ to eliminate moisture of the sample.

${ }^{\mathrm{b}}$ Glass-transition temperature $\left(T_{\mathrm{g}}\right)$ taken as the inflection point of the heating DSC traces recorded at 20 ${ }^{\circ} \mathrm{C} \cdot \mathrm{min}^{-1}$ from melt-quenched samples. Melting temperature $\left(T_{\mathrm{m}}\right)$ and melting enthalpy $\left(\Delta H_{\mathrm{m}}\right)$ measured at a heating rate of $10^{\circ} \mathrm{C} \cdot \mathrm{min}^{-1}$.

The thermal stability was measured in the range of $30-600{ }^{\circ} \mathrm{C}$ range under a nitrogen flow, and the registered TGA traces are compared in Figure 2. As can be seen, the telechelic homopolyester stars to decompose above $300{ }^{\circ} \mathrm{C}$ and displays a unique decomposition step that proceeds at maximum rate at a temperature close to $400{ }^{\circ} \mathrm{C}$. The resistance to heating shown by this polyester is in agreement with data recently reported for their homologous 
polyesters made from other dicarboxylic acids and Glux-diol, which evidenced the ability of the bicyclic diol to enhance the thermal stability of aliphatic polyesters [27]. PLA homopolyester also decomposed in one step but at a considerable lower temperature.

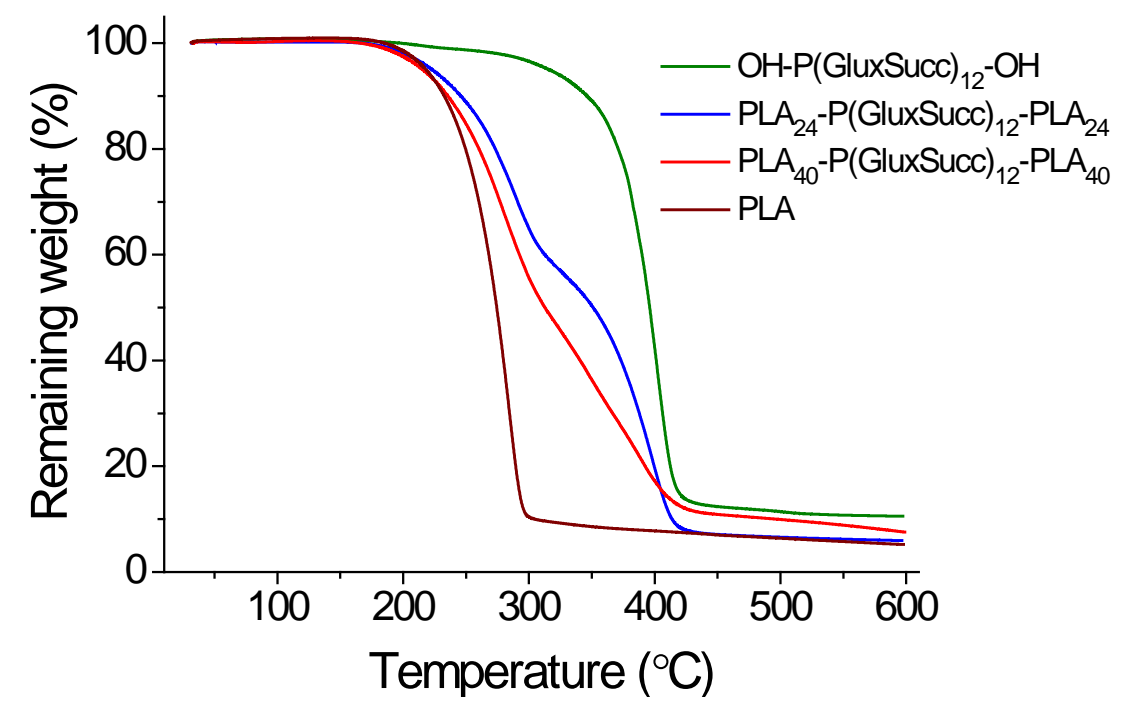

Fig. 2. TGA traces of polyesters.

The triblock copolyesters started to decompose at $\sim 220^{\circ} \mathrm{C}$ due to the relative lower stability of PLA blocks. In contrast to the homopolyesters, PLA $-P(G l u x S u c c){ }_{x}-P L A_{y}$ copolyesters decomposed through several degradation steps along a wide range of temperatures. Main peaks corresponding to temperatures of maximum degradation rates were observed for the derivatives curves of the TGA traces in the $\sim 270-400{ }^{\circ} \mathrm{C}$ range (see ESI file). The weight loss taking place at the lower temperature step is in agreement with that should be expected for the complete degradation of the PLA blocks whereas that happening at higher temperature corresponds approximately to the decomposition of the (GluxSucc) $\mathrm{x}$ block. According to the degradation process followed at each case, the residue left after heating at $600{ }^{\circ} \mathrm{C}$ was maximum for the telechelic homopolyester (11\%) whereas remaining weights for the PLA homopolyester and triblock copolyesters oscillated within the 5-8\% range. These TGA results lead to conclude that although the thermal stability of the copolyesters is significantly 
lower than that of the $\mathrm{OH}-\mathrm{P}(\mathrm{GluxSucc})_{12}-\mathrm{OH}$, these compounds continue being heat resistant enough as to be comfortably handled by thermal processing.

A DSC analysis of the $\mathrm{OH}-\mathrm{P}(\text { GluxSucc })_{12}-\mathrm{OH}$ and PLA homopolyesters and triblock copolyesters was carried out in order to appraise their behavior regarding reversible thermal transitions. The DSC traces recorded at first heating of powdered samples are accessible in the ESI document. Plain traces characteristic of amorphous material were recorded from all samples including PLA. Although according to the optical purity of the L-lactic acid used for feeding, the PLA blocks could be expected to be crystalline, racemization of L-lactide occurring under the applied polymerization conditions led to generation of non-stereoregular blocks unable to crystallize.

The traces recorded from samples quenched from the melt showed inflections characteristic of glass-transitions (see ESI) at temperatures between 40 and $60{ }^{\circ} \mathrm{C}$ (Table 2). The telechelic $\mathrm{OH}-\mathrm{P}(\mathrm{GluxSucc})_{12}-\mathrm{OH}$ homopolyester displayed a pretty high glass-transition temperature $\left(94^{\circ} \mathrm{C}\right)$ as logically corresponds to the chain stiffness induced by the presence of the of the Glux-diol units $[27,28]$. As it is known, the $T_{\mathrm{g}}$ of PLA varies in the range of $50-80{ }^{\circ} \mathrm{C}$ depending on different parameters such as molecular weight and stereoisomeric content $[29,30]$. The PLA synthesized in this work showed a rather low $T_{\mathrm{g}}\left(40^{\circ} \mathrm{C}\right)$ due to both absence of crystallinity and low molecular weight. The triblock copolyesters showed only one $T_{\mathrm{g}}$ at a value intermediate between those of $\mathrm{OH}-\mathrm{P}(\mathrm{GluxSucc})_{12}-\mathrm{OH}$ and PLA, which increased with the GluxSucc/LA ratio as it should be expected. This result demonstrates the miscibility of the GluxSucc and LA blocks, a result that is striking given the constitutional differences between the two blocks. In fact, the GluxSucc structure is expected to be hydrophilic due to the presence of the two fused dioxane rings whereas PLA is unanimously considered a hydrophobic polyester. As we will see below, the two blocks will be however separated out when the copolyester is left to be self-assembled in an aqueous environment.

A preliminary evaluation of the hydrodegradability of the triblock copolyesters was carried out by monitoring the changes taking place in molecular weight as a function of time in samples incubated in aqueous buffer $\mathrm{pH} 7.4$ at $37^{\circ} \mathrm{C}$, both in absence and presence of 
lipases. After three weeks of incubation, the $\mathrm{PLA}_{24}-\mathrm{P}(\text { GluxSucc })_{12}-\mathrm{PLA}_{24}$ copolyester had lost less than $10 \%$ of its initial $M_{\mathrm{w}}$ indicating a moderate sensitivity to hydrolysis under physiological conditions. The ${ }^{1} \mathrm{H}$ NMR spectrum of the products released by the copolyester to the incubating medium revealed the presence of succinic and lactic acid as well as soluble oligomers of different lengths. The figures illustrating these results have been included in the ESI file.

\section{3. $P L A_{y}-P(G l u x S u c c)_{x}-P L A_{y}$ nanoparticles}

Nanoparticles are known to be excellent systems for the adequate transport and distribution of drugs at both cell and organ levels. The nanometer-size ranges of these systems offer distinct advantages as effective permeation through cell membranes and good stability in the blood flow. Nanoparticles of $P L A_{y}-P(\text { GluxSucc })_{12}-P L A_{y}$ were obtained by dialysis-precipitation method using DMSO as organic phase. The most characteristic parameters of the nanoparticles are collected in Table 3. As it is shown in Fig. 3, well-shaped spherical particles with average diameters in the 100-130 nm range and satisfactory dispersities were obtained. The size distribution profiles of the nanoparticles obtained from the two copolyesters are compared in Fig. 4 to show that an unimodal distribution is present in the two cases and that size slightly reduced as the length of the PLA block increased.

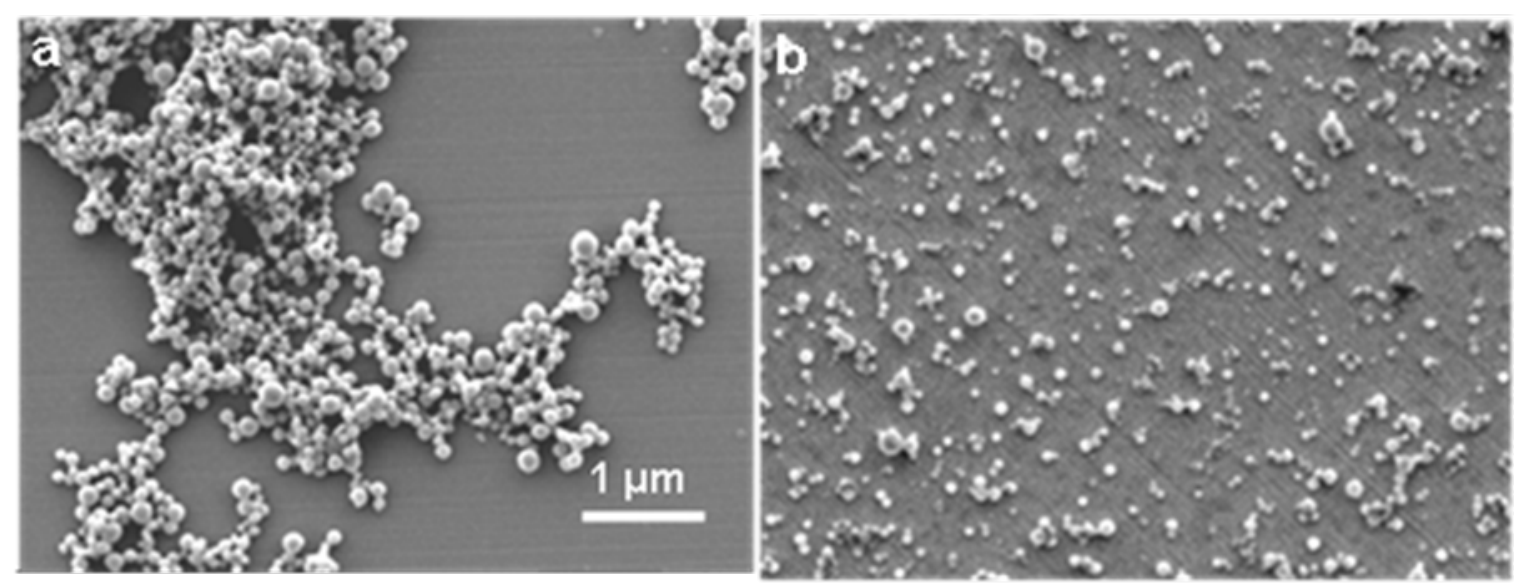

Fig. 3. SEM images of nanoparticles made of $P L A_{24}-P(\text { GluxSucc })_{12}-P L A_{24}(a)$ and $P L A_{40}-P(G l u x S u c c)_{12^{-}}$ $\mathrm{PLA}_{40}(\mathrm{~b})$ triblock copolyesters. 
Table 3. Nanoparticles properties.

\begin{tabular}{|c|c|c|c|c|c|}
\hline \multirow{2}{*}{ Triblock copolyester } & \multirow{2}{*}{ Particle size $(\mathrm{nm})$} & \multirow{2}{*}{$D$} & \multirow{2}{*}{$\zeta$-potential $(\mathrm{mV})$} & \multicolumn{2}{|c|}{ Radius of gyration $(\mathrm{nm})^{a}$} \\
\hline & & & & 1 & $\|$ \\
\hline $\mathrm{PLA}_{24}-\mathrm{P}(\text { GluxSucc })_{12}-\mathrm{PLA}_{24}$ & $123.4 \pm 7.5$ & 0.04 & $-31.1 \pm 1.8$ & $3.30 \pm 0.02$ & $3.17 \pm 0.02$ \\
\hline $\mathrm{PLA}_{40}-\mathrm{P}(\text { GluxSucc })_{12}-\mathrm{PLA}_{40}$ & $109.9 \pm 10.2$ & 0.17 & $-13.9 \pm 1.4$ & $3.08 \pm 0.01$ & $3.11 \pm 0.01$ \\
\hline $\mathrm{PLA}_{60}-\mathrm{P}(\mathrm{GluxSucc})_{12}-\mathrm{PLA}_{60}{ }^{\mathrm{b}}$ & - & - & - & $3.05 \pm 0.01$ & $3.04 \pm 0.01$ \\
\hline
\end{tabular}

${ }^{\text {a }}$ Simulations starting with the chains separated (I), and the chains close to each other (II).

${ }^{\mathrm{b}}$ No experimental data available for this composition.

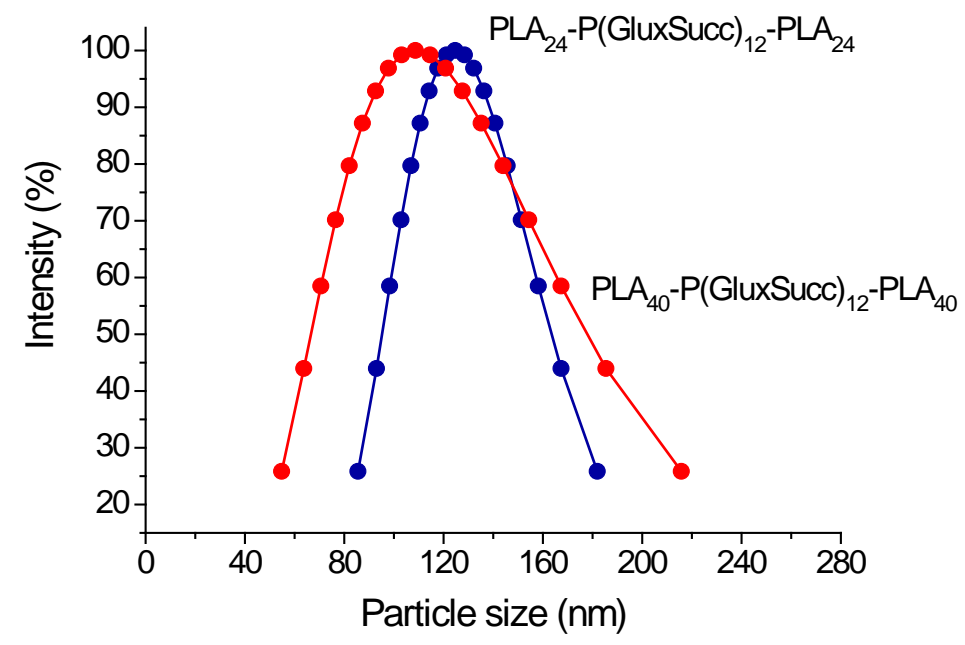

Fig. 4. Size distribution profiles of nanoparticles.

The Zeta potential is a relevant parameter that is closely related to nanoparticle stability, cell adhesion and self-aggregation, and it has therefore significant implications on product performance. The Zeta-potential of the two triblock copolyesters was negative with values ranging between -30 and $-10 \mathrm{mV}$. Such negative values are consistent with the presence of a high concentration of acetal groups on the particle surface. Accordingly the structure of these nanoparticles can be interpreted as the (GluxSucc) ${ }_{12}$ segments are segregated to the outer part of the nanospheres whereas the PLA blocks remain preferably located in the inner part. The $\mathrm{PLA}_{24}-\mathrm{P}$ (GluxSucc) $)_{12}-\mathrm{PLA}_{24}$ nanoparticles distinguish in showing a significantly higher negative zeta potential value $(\sim-30 \mathrm{mV})$, which is a favorable feature for nanoparticle stability since aggregation will be hindered by electrostatic repulsion. $P L A_{40}-P(\text { GluxSucc })_{12}-P L A_{40}$ nanoparticles exhibit much lower zeta potential values and therefore they should be expected to be more prone to degenerate in unspecific aggregates. 
To evaluate the stability of these nanoparticles while standing at temperatures within the physiological range, a sample made of $\mathrm{PLA}_{24}-\mathrm{P}(\mathrm{GluxSucc})_{12}-\mathrm{PLA}_{24}$ was stored for 5 days in distilled water at temperatures comprised between $25^{\circ} \mathrm{C}$ and $45^{\circ} \mathrm{C}$, and changes taking place in size, $\zeta$-potential and shape with time were monitored. Results are shown in Fig.5 where it can be seen that both size and surface charge of the nanoparticles were essentially maintained after incubation at $25{ }^{\circ} \mathrm{C}$ whereas they significantly changed at higher temperatures. In fact, the particle distribution profiles move steadily to higher values and the $\zeta$ potential rapidly increased with incubation temperature, as it should be expected from a disarrangement of the particle structure. The number distribution and volume distribution plots can be seen in the ESI file. These observations were confirmed by SEM which brought out the morphological changes concomitant to the variations observed in size and charge. A set of illustrative pictures is depicted in Fig. 6 which shows how the particles tend to coalesce to form shapeless continuous aggregates that become more prominent as temperature increased. It is worthy to mind that, in full agreement with light scattering measurements (Fig. 5), the appearance of the nanoparticles remained essentially unchanged when incubated at $25^{\circ} \mathrm{C}$. The influence of chain flexibility on particle stability should be considered for explaining these results. As incubation temperature increases the mobility of the copolyester chains is drastically enhanced since it is approaching to the $T_{\mathrm{g}}$ of the whole system.
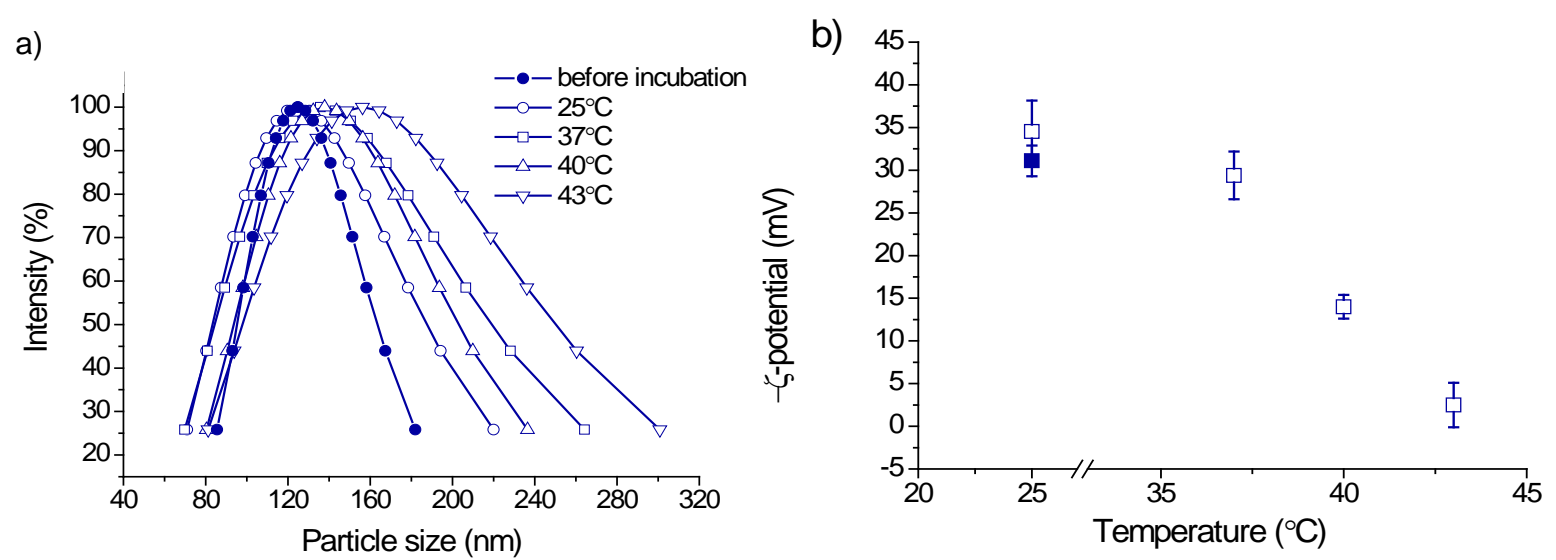

Fig. 5. Particle size distribution (a) and $\zeta$-potential (b) of $P L A_{24}-P(G l u x S u c c)_{12}-P A_{24}$ nanospheres versus temperature after 5 days of incubation in water. 

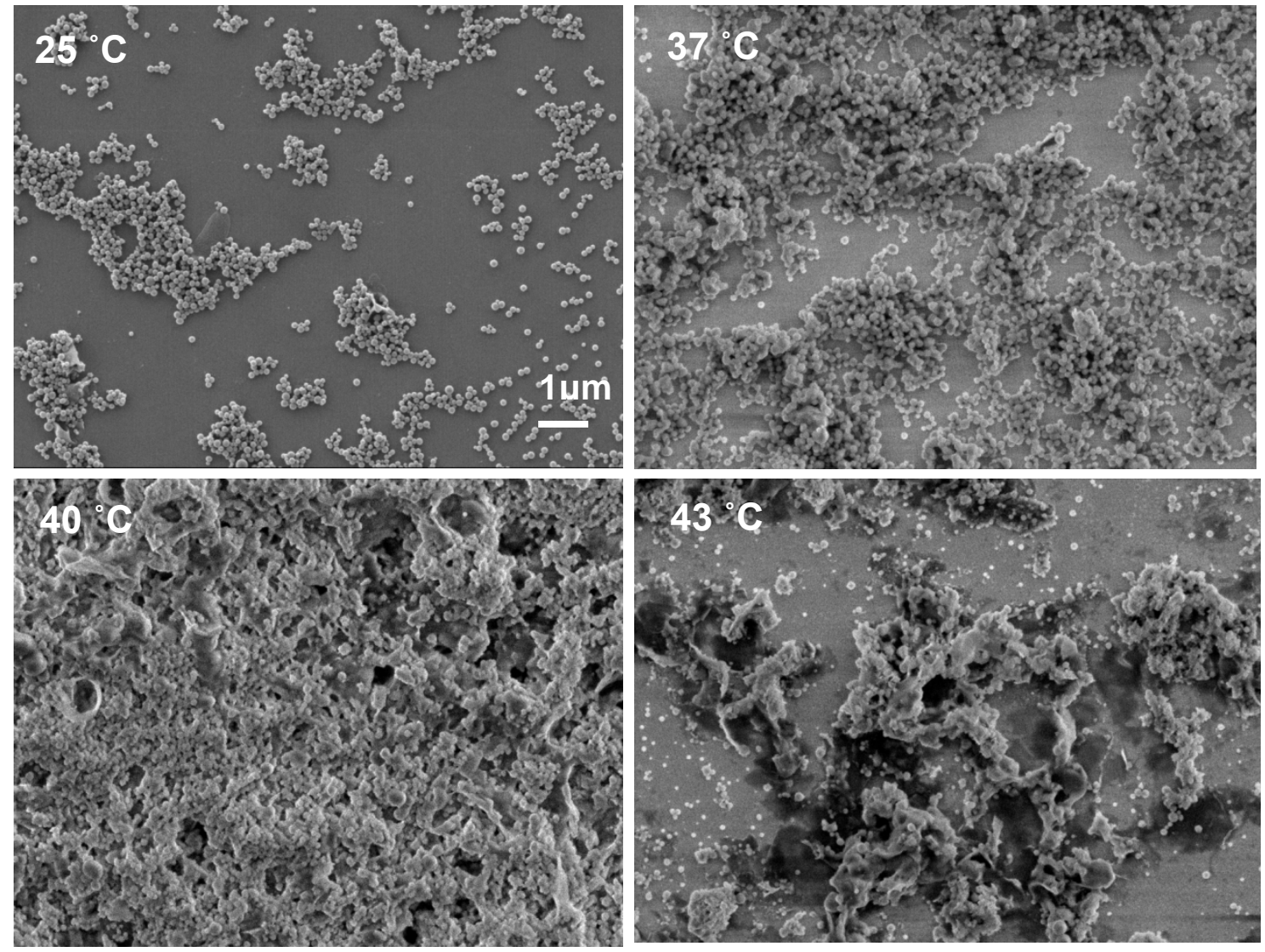

Fig. 6. SEM nanoparticles of $\mathrm{PLA}_{24}-\mathrm{P}(\text { GluxSucc })_{12}-\mathrm{PLA}_{24}$ at $25,37,40$ and $43{ }^{\circ} \mathrm{C}$ after 5 days of incubation in water.

\subsection{Simulation studies}

Mesoscopic molecular dynamics simulations on model nanospheres in aqueous solution have been carried out using the MARTINI force-field [20]. As it is shown in Fig. 7, each repeat unit of the PLA blocks is described by a single non-polar bead, each succinate unit is represented by two polar beads and the Glux unit is represented by four small hydrogen-bonded acceptor beads. A detailed account of the representation used for the copolyester according to the MARTINI framework is given in the ESI document. 


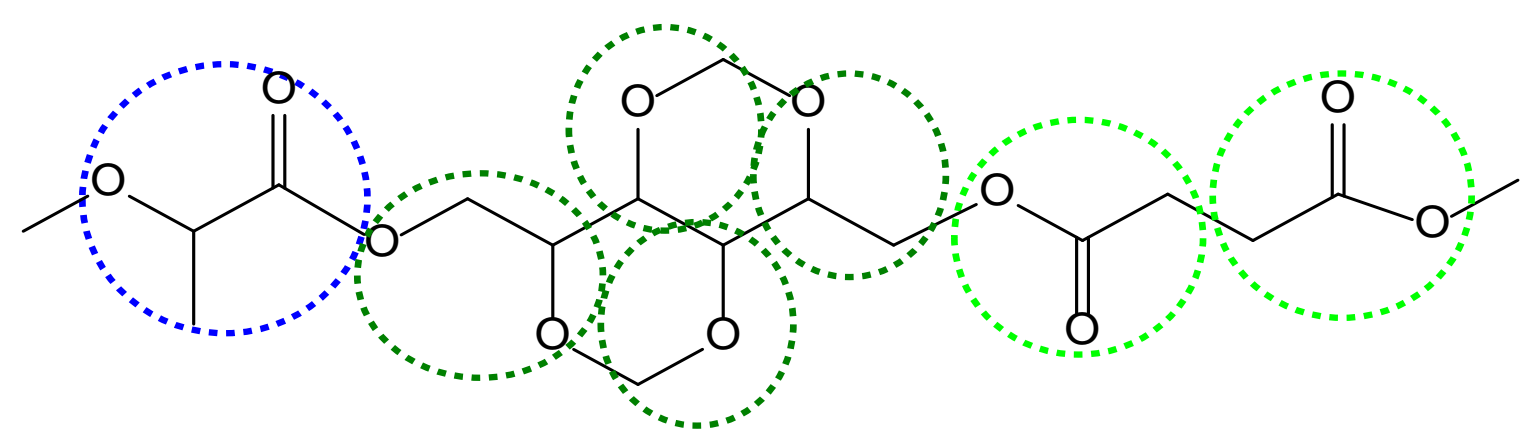

Fig. 7. Scheme illustrating the definition adopted for the CG particles used for the mesoscopic model of the PLA $-P(\text { GluxSucc })_{x}-P L A_{y}$ copolymers. A more detailed sketch indicating the connectivity between the beads is shown in the ESI file.

Triblock copolymer chains PLA $-\mathrm{P}(\text { GluxSucc) })_{12}-\mathrm{PLA}_{\mathrm{y}}$ with PLA blocks of 24, 42, 60 units have been considered in these simulations. In order to more readily compare the results of the different simulations, model nanoparticles with similar weights were built, thus corresponding to 26,19 and 15 chains respectively, for the three lengths of the PLA blocks. All the nanoparticles were placed in a $15 \times 15 \times 15 \mathrm{~nm}^{3}$ solvent box constituted by 27,092 polarizable water particles (equivalent to 108,368 water molecules). In order to avoid artifacts due to the selection of the starting geometry, two molecular dynamics differing in the initial relative chain positions (one with the chains separated from each other, and the other with the chains close to each other) have been performed for each system.

Fig. 8 displays snapshots obtained from the mesoscopic molecular dynamics trajectories for the three selected model nanoparticles. It can be seen that in all cases, the chains tend to aggregate forming a nanoparticle with a roughly spherical shape. In all cases, the hydrophilic GluxSucc groups are distributed on the outer region of the particles, while the more hydrophobic PLA blocks tend to occupy an inner region. The interior of the particles is compact and preferably occupied by units of the PLA blocks, as it could be further demonstrated by serial sectioning of the particle (see images in the ESI file). The results obtained for a given copolymer appear to be in general quite irrespective of the starting geometry selected for the simulation. The only exception is the model particle for $\mathrm{PLA}_{24^{-}}$ $\mathrm{P}(\text { GluxSucc })_{12}-\mathrm{PLA}_{24}$; in this case the simulation starting with the chains initially separated led 
to nanoparticle displaying a more irregular shape, and even two of the chains remained unjointed to the nanoparticle aggregate.

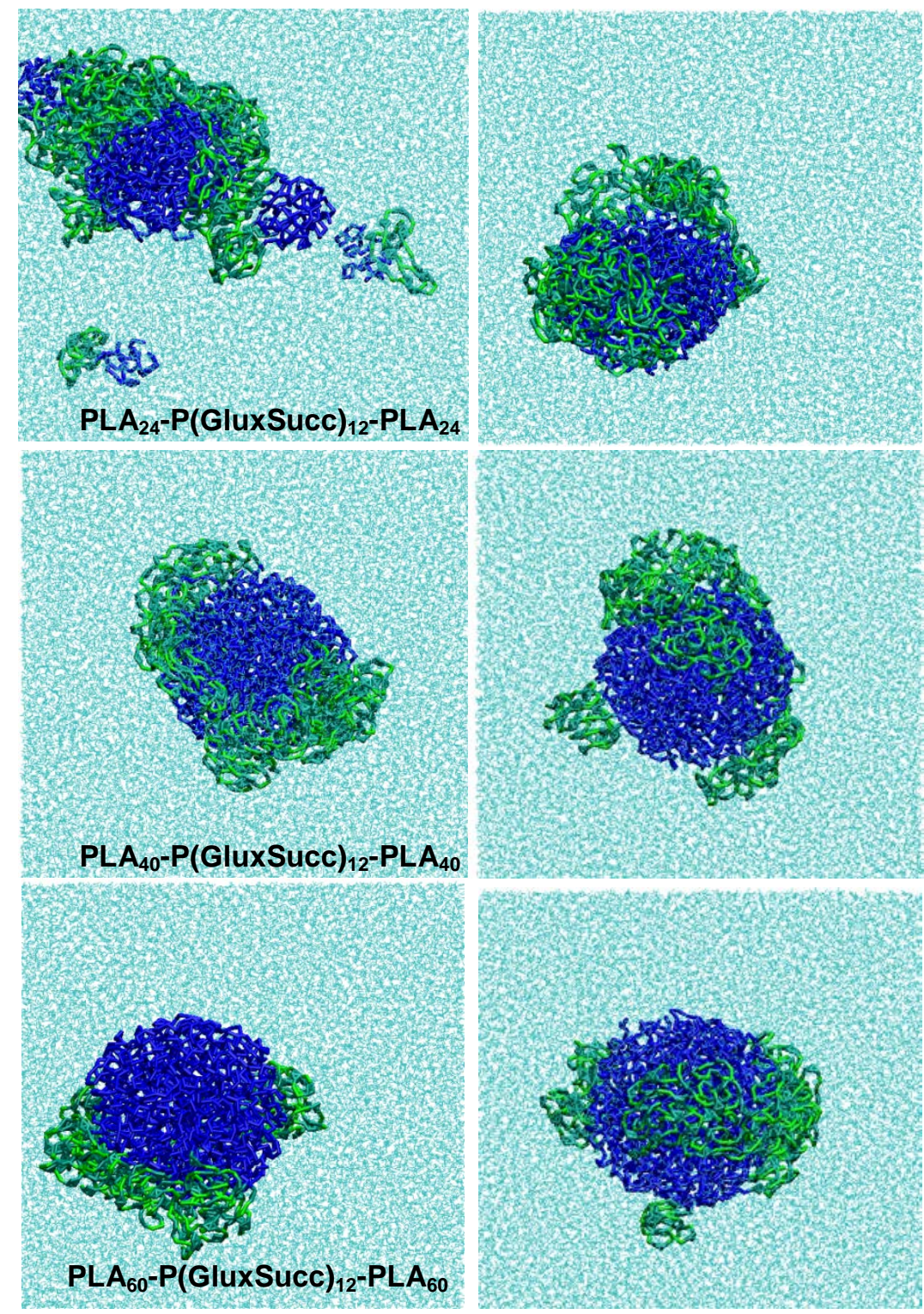

Fig. 8. Snapshots for the solvated model nanospheres of the PLA $-P(G l u x S u c c)_{12}-P L A_{y}$ copolyesters, from trajectories with two different starting geometries. Left: separated chains; Right: closed chains. LA groups are depicted in blue color, Glux groups in dark green and Succ groups in bright green. Water molecules are represented in cyan.

The size of the model nanoparticles has been evaluated in terms of the global radius of gyration, which is displayed in Table 3. Even though the model nanoparticle sizes used for simulations are much smaller than those experimentally produced, the values of the radius of gyration tend to decrease when the length of the PLA block increases, in agreement with 
experimental observations. The distribution of polymer mass and solvent molecules inside the nanoparticles has been analyzed and results are shown in Fig. 9. The dimensions and shape of the model nanospheres were analyzed in terms of the radial distribution of groups. Fig. 9a displays the radial distribution function of the copolymer units with respect to the center of mass of the nanoparticle. In all cases, the inner region presents a rather homogeneous distribution of groups, and extends up until about $3.5 \mathrm{~nm}$ from the center, while the outer groups extend up to $5 \mathrm{~nm}$. Interestingly, although the differences between the three distributions are small, the groups for $\mathrm{PLA}_{24}-\mathrm{P}(\mathrm{GluxSucc})_{12}-\mathrm{PLA} \mathrm{A}_{24}$ are able to reach longer distances from the center.
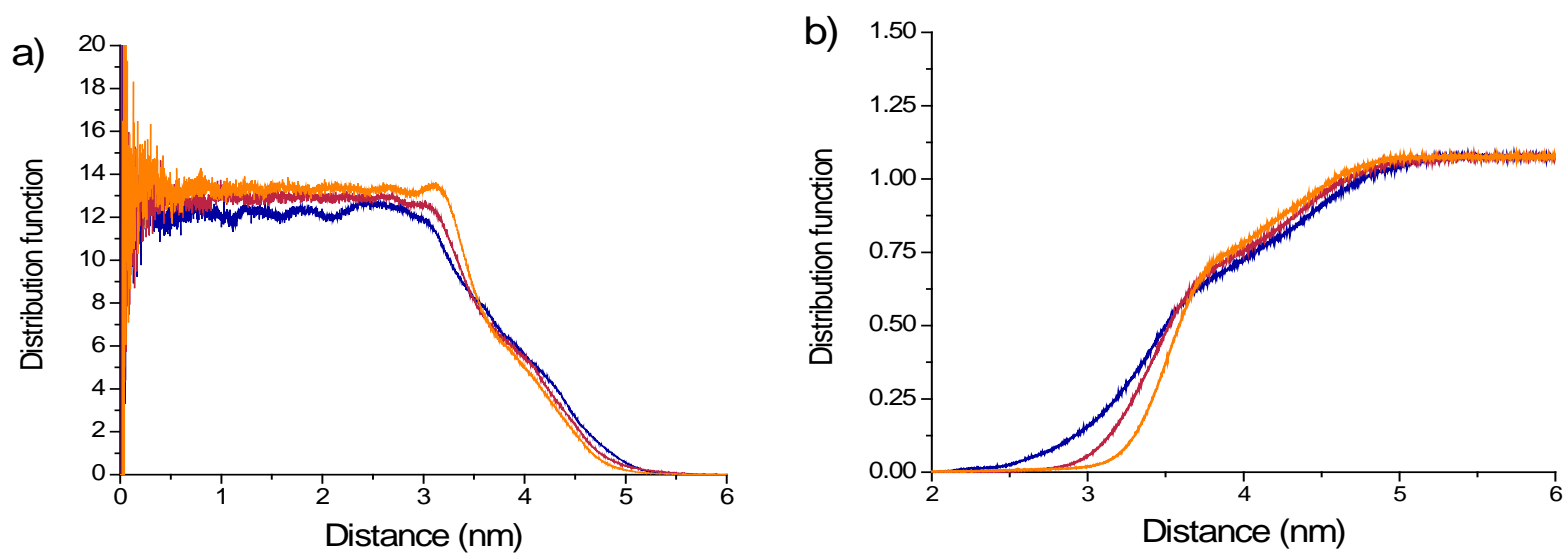

Fig. 9. Radial distribution analysis of the model $P L A_{y}-P(G l u x S u c c)_{12}-P L A_{y}$ nanoparticles. Blue, red and orange colors refer to PLA block size $y=24,42,60$, respectively. Only results for the simulations starting with a close arrangement of chains are shown a) Mass distribution b) Solvent distribution.

Regarding the distribution of solvent around the model nanoparticles, Fig. 9b shows the radial density of solvent with respect to the center of mass of the nanoparticle, which evidences the inexistence of solvent in the interior of the particles. The presence of solvent starts to be detectable at a distance of $2.5-3 \mathrm{~nm}$ from the center and increases with the radius. It should be remarked that the presence of water at distances of $4-5 \mathrm{~nm}$ is due to the fact that the polymer groups are insufficient to fill the spherical space defined at such distances (this can be better appreciated in Fig. 8). 
Finally, the distribution of the different polymer building blocks within the model nanoparticles is illustrated in Fig.10. As it was reflected in the snapshots depicted in Fig. 8, the inner region of the particles is preferably occupied by the hydrophobic PLA blocks, while the hydrophilic GluxSucc units are predominantly placed in the outer region. The differences among the radial density profiles mainly concern the distribution of the outer groups. Such distribution is broader for the systems with shorter PLA segments. This can be observed in
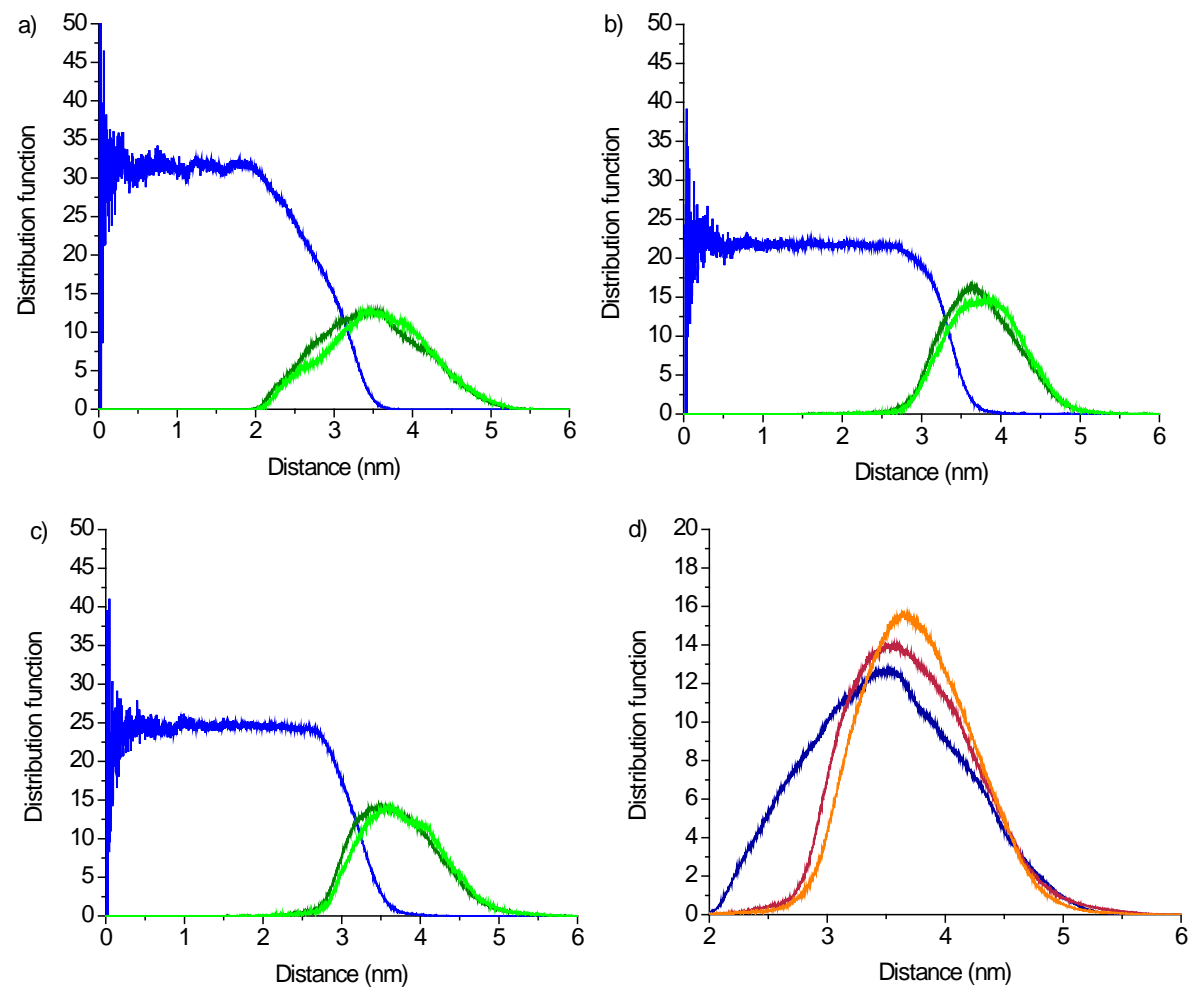

Fig. 10. Radial density of individual LA, Succ and Glux groups with respect to the center of mass of the model PLA $-P(\text { GluxSucc) })_{12}-P L A_{y}$ nanoparticles. Blue, dark green and bright green colors refer to LA, Glux and Succ groups, respectively. Only results for the simulation starting with a close arrangement of chains are shown. a) $\mathrm{PLA}_{24}-\mathrm{P}$ (GluxSucc) ${ }_{12}-\mathrm{PLA}_{24}$ b) $\mathrm{PLA}_{42}-\mathrm{P}$ (GluxSucc) $)_{12}-\mathrm{PLA}_{42}$ c) $\mathrm{PLA}_{60^{-}}$ $P(\text { GluxSucc) })_{12}-P L A_{60}$ d) Radial density of the hydrophilic (GluxSucc) groups with respect to the center of mass of the model PLA $-P\left(\right.$ GluxSucc) ${ }_{12}-$ PLA $_{y}$ nanoparticles. Blue, red and orange colors refer to PLA block size $y=24,42,60$, respectively

more detail when the radial distribution function of the hydrophilic groups is compared for the three model nanoparticles (Fig 10d). For $\mathrm{PLA}_{24}-\mathrm{P}(\text { GluxSucc) })_{12}-\mathrm{PLA}_{24}$, the smaller proportion of PLA blocks with respect to the P(GluxSucc) segment could allow a more readily covering of 
the outer region by the hydrophilic blocks, while for $\mathrm{PLA}_{42}-\mathrm{P}(\mathrm{GluxSucc})_{12}-\mathrm{PLA}_{42}$ and $\mathrm{PLA}_{60^{-}}$ $\mathrm{P}$ (GluxSucc) $)_{12}-\mathrm{PLA} \mathrm{A}_{60}$ the large proportion of PLA segments forces the outer region to have an smaller thickness to cover as much as possible the outer core. It is worth mentioning that the mass placed at the outer region does not cover the whole space around the hydrophobic core. In other words, the number of molecules used for modelling is not large enough as to build an arrangement in which the contact between water and the hydrophobic segments can be fully avoided. Unfortunately, the computational cost to simulate a nanoparticle with the experimental dimensions would exceed largely the scope of the present work.

\section{Conclusions}

Two bio-based triblock copolyesters PLA $-\mathrm{P}(\text { GluxSucc) })_{12}-\mathrm{PLA}_{\mathrm{y}}$ for $\mathrm{y}=24$ and 40 were successfully synthesized via ROP of L-lactide using as initiator a telechelic hydroxyl-capped polysuccinate derived from D-glucose, i.e. OH-P(GluxSucc $)_{12}-\mathrm{OH}$. Racemization of the Llactide happened in the polymerization led to the non-crystalline copolyesters. The copolyesters were slightly biodegradable and their thermal stability was found to increase with the content in Glux units. They showed an only $T_{\mathrm{g}}$ of value intermediate between those of PLA and $\mathrm{P}$ (GluxSucc) indicative of the miscibility of the blocks. The copolyesters were found to be able to form nanoparticles with diameters in the 100 to $130 \mathrm{~nm}$ range which maintained their physical integrity during storage at room temperature but coalesced when temperature increased above $37{ }^{\circ} \mathrm{C}$. The modelling of the nanoparticles by molecular dynamics using a system of moderate dimensions supported the existence of a biphasic structured arrangement with the GluxSucc units preferably located on the periphery and the polylactide blocks filling the inner space. The present research has shown the capacity of these triblock copolyesters to build biphasic nanoparticles suitable as hydrophobic drug carriers in aqueous media, and has brought into evidence their potential to be used as drug delivery systems with the release being controlled by mild temperature changes. 


\section{Acknowledgements}

This work received financial support from MINECO of Spain with Grants MAT2012-38044C03-03 and MAT2016-77345-C3-1-P and from AGAUR with grant 2009SGR1469. Thanks also to MECD of Spain for the Ph.D. grant awarded to Elena Zakharova.

\section{References}

[1] L.S. Nair, C.T. Laurencin, Biodegradable polymers as biomaterials, Prog. Polym. Sci. 32 (2007) 762-798.

[2] H. Tian, Z. Tang, X. Zhuang, X. Chen, X. Jing, Biodegradable synthetic polymers: preparation, functionalization and biomedical application, Prog. Polym. Sci. 37 (2012) 237-280.

[3] S. Doppalapudi, A. Jain, W. Khan, A.J. Domb, Biodegradable polymers - an overview, Polym. Adv. Tech. 25 (2014) 427-435.

[4] I. Manavitehrani, A. Fathi, H. Badr, S. Daly, A.N. Shirazi, F. Dehghani, Biomedical applications of biodegradable polyesters, Polymers 8 (2016) Art $n^{0}: 20$.

[5] Y. Ikada, H.Tsuji, Biodegradable polyesters for medical and ecological applications, Macromol. Rapid Commun. 21 (2000) 117-132.

[6] M. Vert, Aliphatic polyesters: great degradable polymers that cannot do everything, Biomacromolecules 6 (2005) 538-546.

[7] A.P. Gupta, V. Kumar, New emerging trends in synthetic biodegradable polymers polylactide: a critique, Eur. Polym. J. 43 (2007) 4053-4074.

[8] K. Hamad, M. Kaseem, H.W. Yang, F. Deri, Y.G. Ko, Properties and medical applications of polylactic acid: a review, Express Polym. Lett. 9 (2015) 435-455.

[9] K.A. Athanasiou, C.M. Agrawal, F.A Barber, S.S. Burkhart, Orthopaedic applications for PLA-PGA biodegradable polymers, Arthroscopy 14 (1998) 726-737.

[10] K. Garvin, C. Feschuk, Polylactide-polyglycolide antibiotic implants, Clin. Orthop. Rel. Res. 437 (2005) 105-110.

[11] R. Dinarvand, N. Sepehri, S. Manoochehri, H. Rouhani, F. Atyabi, Polylactide-co-glycolide nanoparticles for controlled delivery of anticancer agents, Int. J. Nanomedicine 6 (2011) 877895.

[12] R.Z. Xiao, Z.W. Zeng, G.L. Zhou, J.J. Wang, FZ. Li, A.M. Wang, Recent advances in PEG-PLA block copolymer nanoparticles, Int. J. Nanomedicine 5 (2010) 1057-1065. 
[13] B. Wang, W. Jiang, H. Yan, X. Zhang, Y. Li, L. Deng, G. Singh, J. Pan, Novel PEG-graftPLA nanoparticles with the potential for encapsulation and controlled release of hydrophobic and hydrophilic medications in aqueous medium, Int. J. Nanomedicine 6 (2011) 1443-1451.

[14] J.K. Oh, Polylactide (PLA)-based amphiphilic block copolymers: synthesis, self-assembly, and biomedical applications, Soft Matter 7 (2011) 5096-5108.

[15] T. Li, ; R. Han, M. Wang, C. Liu, X. Jing, Y. Huang, Fusiform micelles from nonlinear poly(ethylene glycol)/polylactide copolymers as biodegradable drug carriers, Macromol. Biosci. 11 (2011) 1570-1578.

[16] H. Arimura, Y. Ohya, T. Ouchi, Formation of core-shell type biodegradable polymeric micelles from amphiphilic poly(aspartic acid)-block-polylactide diblock copolymer Biomacromolecules 6 (2005) 720-725.

[17] C. Japu, A. Martínez de Ilarduya, A. Alla, M.G. García-Martín, J.A. Galbis, S. MuñozGuerra, Bio-based PBT copolyesters derived from D-glucose: influence of composition on properties, Polym. Chem. 5 (2014) 3190-3202.

[18] E. Zakharova, A. Alla, A. Martínez de Ilarduya, S. Muñoz-Guerra, Bio-based PBS copolyesters derived from a bicyclic D-glucitol, RSC Adv. 5 (2015) 46395-46404.

[19] R. Marín, S. Muñoz-Guerra, Carbohydrate-based poly(ester-urethane)s: a comparative study regarding cyclic alditols extenders and polymerization procedures, J. Appl. Polym. Sci. 114 (2009) 3723-3736.

[20] S.J. Marrink, H.J. Risselada, S. Yefimov, D.P. Tieleman, A.H. de Vries, The MARTINI force field: coarse grained model for biomolecular simulations, J. Phys. Chem. B 111 (2007) 7812-7824.

[21] S.O. Yesylevskyy, L.V. Schafer, D. Sengupta, S.J. Marrink, Polarizable water model for the coarse-grained MARTINI force field, PLOS Computational Biology 6 (2010) e1000810.

[22] C. Oostenbrink, A. Villa, A.E. Mark, W.F. van Gunsteren, A biomolecular force field based on the free enthalpy of hydration and solvation: the GROMOS force-field parameter sets 53A5 and 53A6. J. Comput. Chem. 25 (2004) 1656-1676.

[23] A.K. Malde, L. Zuo, M. Breeze, M. Stroet, D. Poger, P.C. Nair, C. Oostenbrink, A.E. Mark, An automated force field topology builder (ATB) and repository: version 1.0, J. Chem. Theory Comput. 7 (2011) 4026-4037.

[24] S. Canzar, M. El-Kebir, R. Pool, K. Elbassioni, A.K. Malde, A.E. Mark, D.P. Geerke, L. Stougie, G.W. Klau, Charge group partitioning in biomolecular simulation, J. Comp. Biol. 20 (2013) 188-198.

[25] K.B. Koziara, M. Stroet, A.K. Malde, A.E. Mark, Testing and validation of the automated topology builder (ATB) version 2.0: prediction of hydration free enthalpies, J. Comput. Aided Mol. Des. 28 (2014) 221-233.

[26] A.P. Eichenberger, J.R. Allison, J. Dolenc, D.P. Geerke, B.A.C. Horta, K. Meier, C. Oostenbrink, N. Schmid, D. Steiner, D.Q. Wang, W.F. van Gunsteren, GROMOS plus software 
for the analysis of biomolecular simulation trajectories, J. Chem. Theory Comput. 7 (2011) 3379-3390.

[27] E. Zakharova, A. Martínez de Ilarduya, S. León, S. Muñoz-Guerra, Sugar-based bicyclic monomers for aliphatic polyesters: a comparative appraisal of acetalized alditols and isosorbide, Des. Monomers Polym. 20 (2016) 157-166.

[28] C. Japu, A. Martínez de Ilarduya, A. Alla, M.G. García-Martín, J.A. Galbis, S. MuñozGuerra, D-Glucose-derived PET copolyesters with enhanced $T_{\mathrm{g}}$, Polym. Chem. 4 (2013) 35243536.

[29] J. Ahmed, J.X. Zhang, Z. Song, S.K. Varshney, Thermal properties of polylactides: effect of molecular mass and nature of lactide isomer, J. Thermal Anal. Calorim. 95 (2009) 957-964. 